\title{
THIGH AND CALF DISCRIMINATION IN THE MOTOR INNERVATION OF THE CHICK HINDLIMB FOLLOWING DELETIONS OF LIMB SEGMENTS ${ }^{1}$
}

\author{
VIRGINIA WHITELAW ${ }^{*, 2}$ AND MARGARET HOLLYDAY $\ddagger^{3}$ \\ * Department of Biophysics and Theoretical Biology and $\ddagger$ Department of Pharmacological and Physiological Sciences, \\ The University of Chicago, Chicago, Illinois 60637
}

Received August 11, 1982; Revised December 27, 1982; Accepted January 17, 1983

\begin{abstract}
In this paper we report studies on the organization of the motor projections to chick hindlimbs lacking limb segments as a result of surgical manipulations during early embryonic development. The innervation of partial limbs, missing either a thigh or both a calf and a foot, was studied using both retrograde and orthograde horseradish peroxidase nerve-tracing techniques, as well as by serial reconstruction. In addition, $\left[{ }^{3} \mathrm{H}\right]$ thymidine autoradiography was used to characterize motoneuron production and loss. Motor organization was assessed both before and after the period of naturally occurring motoneuron death.

Prior to the period of cell death, we verified by autoradiography that the organization of the motor column (i.e., motoneuron birthdates and settling patterns) was normal despite deletions of the periphery. It was also found that, initially, the entire motor column projected to the partial limbs, entering via normal crural and sciatic pathways. The proximal branching patterns of the nerves leaving the plexus were normal; however, the distal projections of the nerves which would normally serve the missing limb segment were truncated.

After the period of cell death, the motor columns serving segment-deleted limbs were excessively and selectively depleted of target-deprived motoneurons. The remaining motor pools appropriately innervated their normal targets. Thus, when both thigh- and calf-serving motor axons invaded a given limb segment, only the axons which normally serve that segment successfully innervated it.

Our findings on the innervation of partial limbs cannot be explained on the assumption that motor projection patterns are determined solely by the timing or spatial arrangement of axon arrival at the limb bud. They indicate that motor axons destined to innervate thigh and calf muscles differ from one another such that their initial growth trajectories are distinctive and their final termination sites are appropriate for the muscles available. These differences are evident both from the pattern of selective cell death and from the normal projections of the surviving motoneurons.
\end{abstract}

In the chick, as in many other vertebrates, limb muscles receive motor innervation from discrete clusters of neurons in the lateral motor column (LMC) (Romanes, 1951, 1964). The motoneurons that innervate a given muscle are called the motor pool for that muscle. The motor projection to the chick hindlimb has been described using both anatomical and electrophysiological techniques (Landmesser and Morris, 1975; Landmesser,

\footnotetext{
${ }^{1}$ This work was supported by National Institutes of Health Grant NS-14066 to M. H. V. W. was supported by United States Public Health Service Grants GM-07183, GM-07839, and NS-14066. We thank Dr. Paul Grobstein for valuable discussions and for help in writing this paper.

${ }^{2}$ Present address: Bell Laboratories, Naperville, IL 60566.

${ }^{3}$ To whom correspondence should be sent at Department of Pharmacological and Physiological Sciences, University of Chicago, 947 East 58th Street, Chicago, IL 60637.
}

1978a; Hollyday, 1980). To a large extent, the motor pool map is continuous: neighboring muscles in the limb are served by neighboring motor pools in the spinal cord. This permits the hypothesis that the normal motor projection could be organized solely by fiber sorting among neighboring axons or by the timing and spatial arrangement of axonal arrival at the embryo (Horder, 1978; Bennett et al., 1980). Alternatively, intrinsically individuated motor axons might recognize and respond to cues in the limb bud, irrespective of the spatial arrangement of the limb precursor tissue or the temporal pattern of axon ingrowth. Such a recognition process might preclude motor axons from reaching inappropriate targets, or it might allow axons to grow to inappropriate targets but put them at a competitive disadvantage in forming synapses (Sperry and Arora, 1965).

We have explored these various possibilities by exam- 
ining motor organization in animals in which the normal neighbor relationships among the limb muscles were disrupted by deletions of embryonic limb segments. If recognition of pathways or position in the limb bud is a dominant influence in the development of the motor pool map, one might expect that target-deprived motoneurons would fail to form synapses and perhaps would die, while the remaining limb muscles would be served by their usual motor pool. Alternatively, if the motor projection is dominated by organizing principles which do not involve recognition of cues in the limb bud, such as timing of axon arrival or maintenance of fiber neighbor relationships, one would expect the motoneurons to innervate the limbs in a pattern that relates to muscle location in the truncated limb rather than to muscle identity.

In the present study, the normal neighbor relations of limb muscles were altered by surgically producing embryos having thigh-deleted or calf- and foot-deleted legs. The motor projection to such limbs was analyzed before and after the period of naturally occurring cell death using both retrograde and orthograde transport of horseradish peroxidase (HRP). In addition, $\left[{ }^{3} \mathrm{H}\right]$ thymidine autoradiography was used to demonstrate that, prior to the period of cell death, the organization of the motor column (i.e., motoneuron birthdates, migration and settling patterns) was not disrupted by deletions in the periphery. The $\left[{ }^{3} \mathrm{H}\right]$ thymidine labeling also provided an independent marker of motoneuron identity which proved important in characterizing the innervation of muscles in partially deleted limbs.

A preliminary account of some of this work has been published (Whitelaw and Hollyday, 1980).

\section{Materials and Methods}

All experiments were performed on White Leghorn chick embryos, staged according to the system of Hamburger and Hamilton (1951). Fertilized eggs were obtained from local hatcheries and incubated at $99^{\circ} \mathrm{F}$ $\left(38^{\circ} \mathrm{C}\right)$ in a forced draft incubator. After 2 to 3 days of incubation, windows were sanded in the eggs and sealed with glass coverslips held on by paraffin. This provided access to the embryos so that limb manipulations could be performed in ovo at later times.

Surgery. Previous embryological studies of the chick limb have identified regions of the precursor limb bud from which each limb segment develops (Saunders, 1948; Stark and Searls, 1973). The design of the limb manipulations was based on these fate maps.

All operations were performed prior to the stage at which axons grow into the limb bud. The right hindlimb bud was made accessible by carefully tearing back the overlying membranes. Cuts were made with a fine scalpel and forceps.

Calf (and foot) deletions were performed on embryos at stages 20 to 21 . The distal half of the leg bud was excised. A schematic diagram of the operation is shown in Figure $1 a$.

Thigh-deleted animals were produced using a stage (St) 18 host and a slightly older (St 21 to 22 ) donor. The host's right leg bud was removed. The distal third of the donor's right leg bud (including the apical ectodermal ridge) was excised and transferred. The graft was fitted
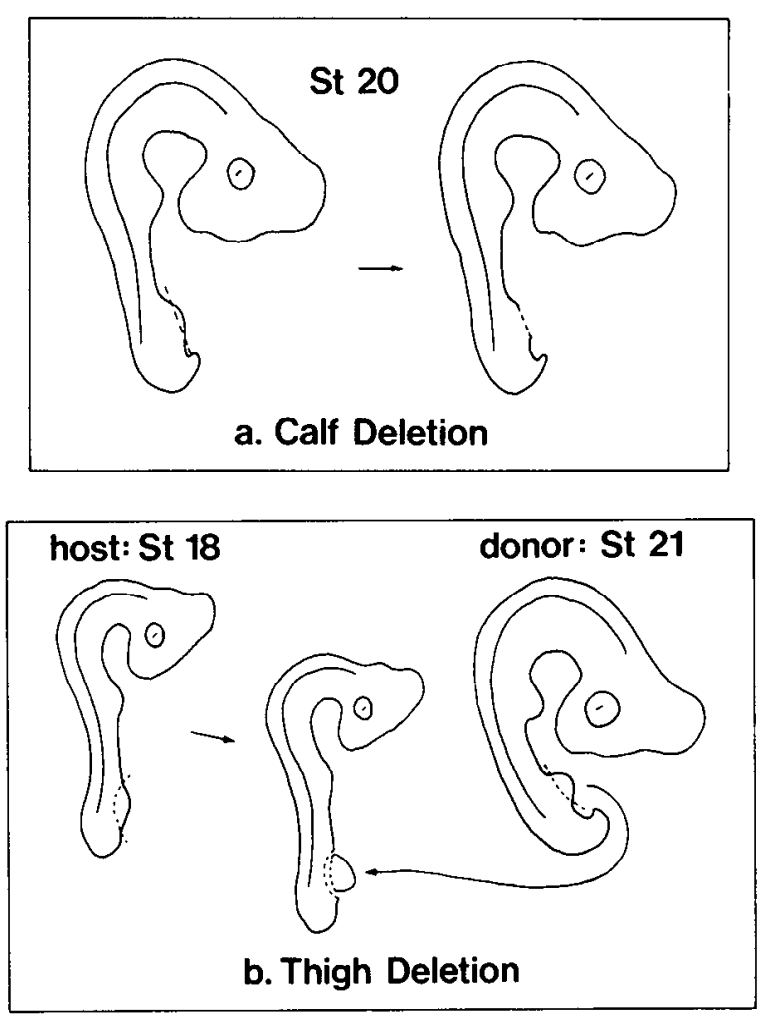

Figure 1. Schematic representation of calf and thigh deletion operations. For a calf deletion $(a)$, calf precursor tissue was removed from a St 20 embryo. For a thigh deletion $(b)$, calf precursor tissue was transferred from a St 21 donor to a slightly younger host whose leg bud had been removed. All operations were performed on the right leg bud.

into the concavity where the host's right leg had been. Excess fluid was wicked away such that the surrounding amniotic membrane tightened around the grafted tissue and secured it. The thigh deletion operation is shown in schematic form in Figure $1 b$.

Following surgery, the embryos were returned to the incubator, either until day 6 (St 28), at which time their pre-cell death projection patterns were studied, or until days 10 to 12 (St 36-38), at which time their adult-like motor pool projections were studied. Several hundred embryos were operated on; of these, 74 survived until the desired stage, had appropriate deletions, and gave successful histological results.

$H R P$ injections and histological analysis. Intramuscular injections of a 20 to $30 \%$ solution of HRP (Sigma Chemical Co., Type VI) dissolved in sterile Ringer's solution were used to map the location of motor pools projecting to individual muscles or groups of muscles. The injections were done either in ovo or in organ culture. The latter method afforded access to deep and medially lying muscles which were difficult to $\cdots$ pose for injections in ovo. All injections were done using a 10- $\mu$ l Hamilton syringe fitted with a pulled glass tip (approximately 100 $\mu \mathrm{m}$ in diameter) held on by paraffin. The protocol for the in ovo injections has been described previously (Hollyday, 1980).

For injections done in organ culture (adapted from Landmesser, 1978a), the embryo was removed from its 
shell and perfused through the heart with oxygen-enriched Tyrode's solution. The embryo's viscera were removed; however, the head and beating heart were left intact. The left (nonexperimental) leg and the ventral cartilage underlying the spinal cord were also removed in most cases, to facilitate exposure of the ventral horn to the oxygenated Tyrode's solution in which the preparation was bathed.

The experimental leg was dissected as necessary to expose the muscle or group of muscles which were to be injected. The injection sizes varied between 0.01 and 1 $\mu \mathrm{l}$, depending on the desired localization of the injection and the size of the muscle. The size of the motor pool mapped by HRP injection would be underestimated if the injection did not fill the entire muscle and overestimated if the HRP leaked to neighboring muscles. Deliberate variation in the size of the injections helped to control for these problems.

Following injection, the preparation was placed in a shallow dish with oxygenated Tyrode's solution. The dish was placed inside a larger chamber into which a $95 \% \mathrm{O}_{2}$ / $5 \% \mathrm{CO}_{2}$ gas mixture was fed. The gas was pre-bubbled through water and the chamber was kept very moist to minimize evaporation of the Tyrode's solution. The chamber was put on a slow shaker table and kept at room temperature for a period of 4 to $8 \mathrm{hr}$. In some animals, jerky leg motions persisted throughout this incubation period. A drop of $1 \%$ norepinephrine (in sterilized Ringer's) was added to most of the preparations to stimulate heart beat. Following this incubation period, the spinal cords and legs were cut apart and fixed separately, as described previously (Hollyday, 1980).

The spinal cords were embedded in gelatin, and frozen sections 40 to $70 \mu \mathrm{m}$ thick were cut transverse to the rostrocaudal axis of the spinal cord. The sections were processed for HRP reaction product using Hanker-Yates reagent (Hanker et al., 1977), which gave a grainy brown reaction product. The sections were mounted on slides and lightly counterstained with cresyl violet. Light microscopic serial reconstructions were made using brightfield optics. Sections were drawn with the aid of a drawing tube.

$\left[{ }^{3} H\right]$ Thymidine autoradiography. In order to interpret the motor pool labeling experiments, we had to identify motoneurons unambiguously in terms of their normal targets. This is normally done on the basis of the predictable relation between motoneuron location in the spinal cord and muscle innervated. However, as described below, subsequent to the period of normal cell death there were obvious changes in the appearance of the LMC. This made it desirable to have an independent way of characterizing the organization among motoneurons. The predictable relation between motoneuron birthdate and motoneuron position proved useful for this purpose.

Figure 2 shows the normal organization of the lumbar LMC, overlaid with the approximate stages at which each motor pool becomes postmitotic (from Hollyday and Hamburger, 1977; Hollyday, 1980; and M. Hollyday, unpublished observations). Shown is a series of drawings of the motor column in cross-section between ventral roots 23 and 30 . Morphologically distinct motoneuron clusters are outlined: motor pools that normally inner- vate thigh muscles are stippled, motor pools for calf muscles are white, and motor pools for intrinsic foot muscles are lined. Motoneurons belonging to the medial motor column serving axial musculature are shown in black. The numbers on each motoneuron cluster in Figure 2 indicate the first stage at which the majority of motoneurons in that pool fail to incorporate $\left[{ }^{3} \mathrm{H}\right]$ thymidine; i.e., are postmitotic. There are clear rostral-to-caudal and medial-to-lateral gradients in motoneuron birthdates. If $\left[{ }^{3} \mathrm{H}\right]$ thymidine is administered approximately midway through the period of motoneuron birthdates, the radioactive label is restricted to the lateral motor pools. At several segmental levels, this provides a nonposition-dependent criterion for distinguishing thigh from calf motor pools. In normal embryos, motoneurons labeled by $\left[{ }^{3} \mathrm{H}\right]$ thymidine at St 20 to 21 are thigh motoneurons; unlabeled cells are calf motoneurons.

Labeling was accomplished by dripping a $20-\mu \mathrm{l}$ dose of $\left[{ }^{3} \mathrm{H}\right]$ thymidine $(6.7 \mu \mathrm{Ci} / \mathrm{mmol})$ onto the chorioallantoic membrane of calf- or thigh-deleted embryos at St 18 to 22 . The autoradiographic labeling pattern in the motor column was studied both before and after the period of cell death. Some of the experimental animals were perfused and fixed in Carnoy's fixative and then paraffin embedded and sectioned at $15 \mu \mathrm{m}$. Alternatively, some of the embryos having $\left[{ }^{3} \mathrm{H}\right]$ thymidine were also injected with HRP and were processed for frozen sections, as described earlier. After the frozen or paraffin sections were mounted on slides (and before counterstaining), they were dipped in nuclear track emulsion (Kodak NTB2) which had been diluted 1:1 in warm distilled watcr. The slides were allowed to dry for several hours in high humidity $(90 \%)$. They were then stored in boxes with desiccant for 4 to 8 weeks at $-70^{\circ} \mathrm{C}$. Before developing, the slides were allowed to warm up to room temperature in a desiccator. They were developed in D19 developer (Kodak) and then lightly counterstained in cresyl violet.

Light microscopic serial reconstructions were made of the autoradiographic labeling patterns. When ${ }^{3} \mathrm{H}$ and HRP were both present in the same cells, the labels were distinct by virtue of the different color of the granular label and the focal plane with which it was associated.

Reconstructions of the limb muscles and peripheral innervation patterns. Segment-deleted limbs were operationally defined by the presence or absence of skeletal elements. A thigh-deleted leg lacked a femur, a calfdeleted leg lacked a tibia, fibula, and font. Only embryos with histologically confirmed deletions were used in this study.

In most of the pre-cell death embryos studied (St 28), the legs were left attached to the spinal cord and were sectioned along with it. Even in thick $(40$ to $60 \mu \mathrm{m})$ frozen sections, there was no difficulty in identifying the limb cartilage and verifying the deletion. In addition to segment-deleted embryos, several animals were produced with complete limb extirpations. The success of this operation was confirmed histologically by the absence of any skeletal elements.

The manipulated limbs from post-cell death embryos (St 36-38) were examined after staining for cartilage in methylene blue (Hamburger, 1960). Upon clearing in amyl acetate or benzene, it was determined whether the 

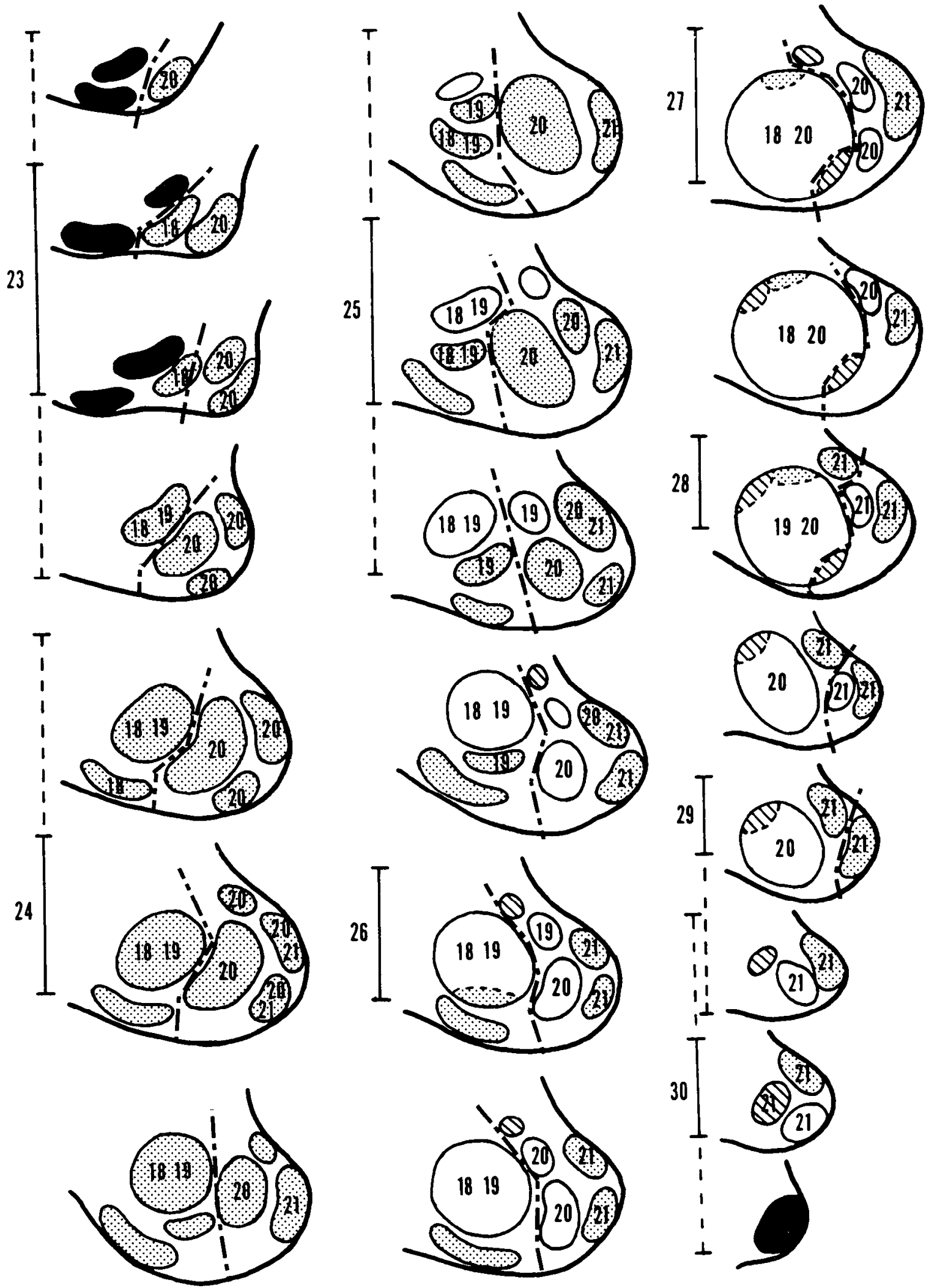

Figure 2. Motoneuron birthdates superimposed on the normal motor pool map. VRs 23 through 30 are shown in spinal crosssection with the motoneuron clusters serving the hindlimb muscles outlined. Thigh-serving motor pools are stippled, calf motor pools are white, and foot motor pools are lined. The medial motor column is shown in black. The numbers in each motor pool refer to the first stage at which the majority of its motoneurons fail to incorporate $\left[{ }^{3} \mathrm{H}\right]$ thymidine; i.e., are postmitotic. Rostral-tocaudal as well as medial-to-lateral gradients of motoneuron birthdates are evident. A dashed line is drawn through each crosssection delineating the motor pools serving ventrally derived muscles (on the left) from those innervating dorsally derived muscles (on the right). 
skeletal elements were appropriate for the operation performed. Appropriate legs were then drawn under a dissecting microscope (using a drawing tube), paraffin embedded, and sectioned at $15 \mu \mathrm{m}$. The sections were stained in hematoxylin and eosin. A microfilm readerprinter ( $3 \mathrm{M}$, Series 500 ) was used to magnify and photograph every tenth section which greatly aided the reconstruction process. Several normal legs were also processed this way and were sectioned in various planes to aid in muscle identification in the manipulated limbs.

Muscles were identified in normal limbs by a number of criteria: origin, insertion, relative position, grain pattern, distinctive tendon (e.g., iliofibularis), or distinctive association with another muscle (e.g., caudilioflexorius and accessorius). Muscles in manipulated limbs were similarly identified by these criteria, although for each of the operations, some of the criteria did not apply. In most of the manipulated limbs, it was possible to identify unambiguously each of the major limb muscles. Data from animals in which such identification was not possible were discarded.

The peripheral nerves innervating manipulated limbs were studied both in sections of embryos whose limb muscles had been injected with HRP and by the orthograde transport of HRP. For the latter, injections of HRP were made directly into the spinal cords of embryos in organ culture. HRP was taken up by motoneuron soma and transported orthogradely into the limb bud. Injected embryos were allowed to transport for 4 to $5 \mathrm{hr}$ and were fixed for HRP histochemistry. Transverse $60-\mu \mathrm{m}$ sections of entire embryos were made with an Oxford Vibratome and the sections were processed with cobalt and diaminobenzidine according to the procedure of Adams (1977). Sections were then lightly counterstained with cresyl violet to aid in the identification of cartilage and limb muscles. In our material, solidly filled axons and axon bundles could be traced in serial sections from their origin in the spinal cord into the limb buds.

The major nerves (femoral, obturator, and the peroneal and tibial components of the sciatic) were identified by their point of entry into the limb and by their relationship to the various skeletal elements and limb muscles. The pattern in which individual muscle nerves branched off these major nerve trunks was assessed in serial reconstructions.

\section{Results}

Before cell death: Normal organization and projection of the motor column into segment-deleted limbs

Organization of the motor column. At St 28, which is just before the onset of cell death in the lumbar LMC, the migration of motoneurons into the ventral horn is essentially complete; the individual clusters of motoneurons, however, are not yet distinct. A total of 17 embryos that received a $\left[{ }^{3} \mathrm{H}\right]$ thymidine injection during the period when motoneurons are being born were examined including 4 total amputees, 6 calf-deleted embryos, and 7 thighdeleted embryos.

In all embryos, irrespective of the type of operation or the stage at which $\left[{ }^{3} \mathrm{H}\right]$ thymidine was applied, the pattern of autoradiographic labeling was the same on the experimental side as on the normal, unoperated side. Early $\left[{ }^{3} \mathrm{H}\right]$ thymidine treatment (St 18, 3 cases) labeled all but the most rostromedial motoneurons; late $\left[{ }^{3} \mathrm{H}\right]$ thymidine treatment (St 22, 4 cases) labeled virtually no cells in the motor column. Treatment at in-between stages (10 cases) labeled a laterally lying fraction of the motoneuron population. This is essentially the same pattern as that observed in normal embryos.

Figure 3 is a photomicrograph of a cross-section through the lumbar LMC of a St 28 embryo in which one entire leg was amputated. The embryo was given a dose of $\left[{ }^{3} \mathrm{H}\right]$ thymidine at $\mathrm{St} 20^{1 / 2}$, and the characteristic medial-to-lateral gradient of autoradiographic label is evident on both sides of the cord. Identical labeling results were obtained for amputated, thigh-deleted, and calfdeleted embryos exposed to $\left[{ }^{3} \mathrm{H}\right]$ thymidine at stage $20 \frac{1}{2}$; at all levels of the spinal cord, cells in the medial and intermediate motoneuron clusters were unlabeled and cells in the far lateral motoneuron clusters were labeled with autoradiographic grains. Hence, motoneurons leave the mitotic cycle over a normal time course, undergo migration, and settle in a characteristic position in the motor column, irrespective of the presence or absence of limb segments.

Motor innervation of the periphery. In addition to assessing the normalcy of LMC organization prior to cell death, it was of interest to know whether all of the motor axons were projecting to the partial limbs. To investigate this question, both retrograde and orthograde nerve-tracing techniques were used. In nine embryos (five calfdeletions, four thigh-deletions), large injections of HRP were made into the limbs. Six of these embryos also received $\left[{ }^{3} \mathrm{H}\right]$ thymidine injections during the period of motoneuron birthdates.

Figure 4 shows two representative cross-sections of the lumbar LMC in a thigh-deleted embryo. This animal received $\left[{ }^{3} \mathrm{H}\right]$ thymidine at $\mathrm{St} 201 / 2$ and a large HRP injection into its thigh-deleted limb at St 28 . Heavy HRP label, covering the entire LMC, as well as the characteristic medial-to-lateral autoradiographic gradients, are evident. Figure $4 a$ is taken from the level of ventral root (VR) 25 , Figure $4 b$ is from VR 27 . In the adult motor pool map, there are primarily thigh motor pools at the first of these levels and calf motor pools at the second. Near-total HRP labeling of motoneurons at both levels indicates that both presumptive thigh and calf motor axons reached the thigh-deleted limb. Near-total HRP filling of the motor column was obtained consistently in all nine limb segment-deleted animals examined.

More detailed information on the response of motor axons to the altered periphery during their early stages of outgrowth was obtained using orthograde transport of HRP. It was of particular interest to know in thighdeleted embryos whether the motor axons which would normally innervate the thigh actually penetrated the grafted distal tissue or whether they stopped growing close to their point of entry into the partial limb. These two possibilities could not be distinguished by the retrograde labeling studies; however, they could be distinguished using orthograde tracing techniques. Therefore, we made HRP injections into spinal cord regions that would normally innervate the anterior thigh exclusively 


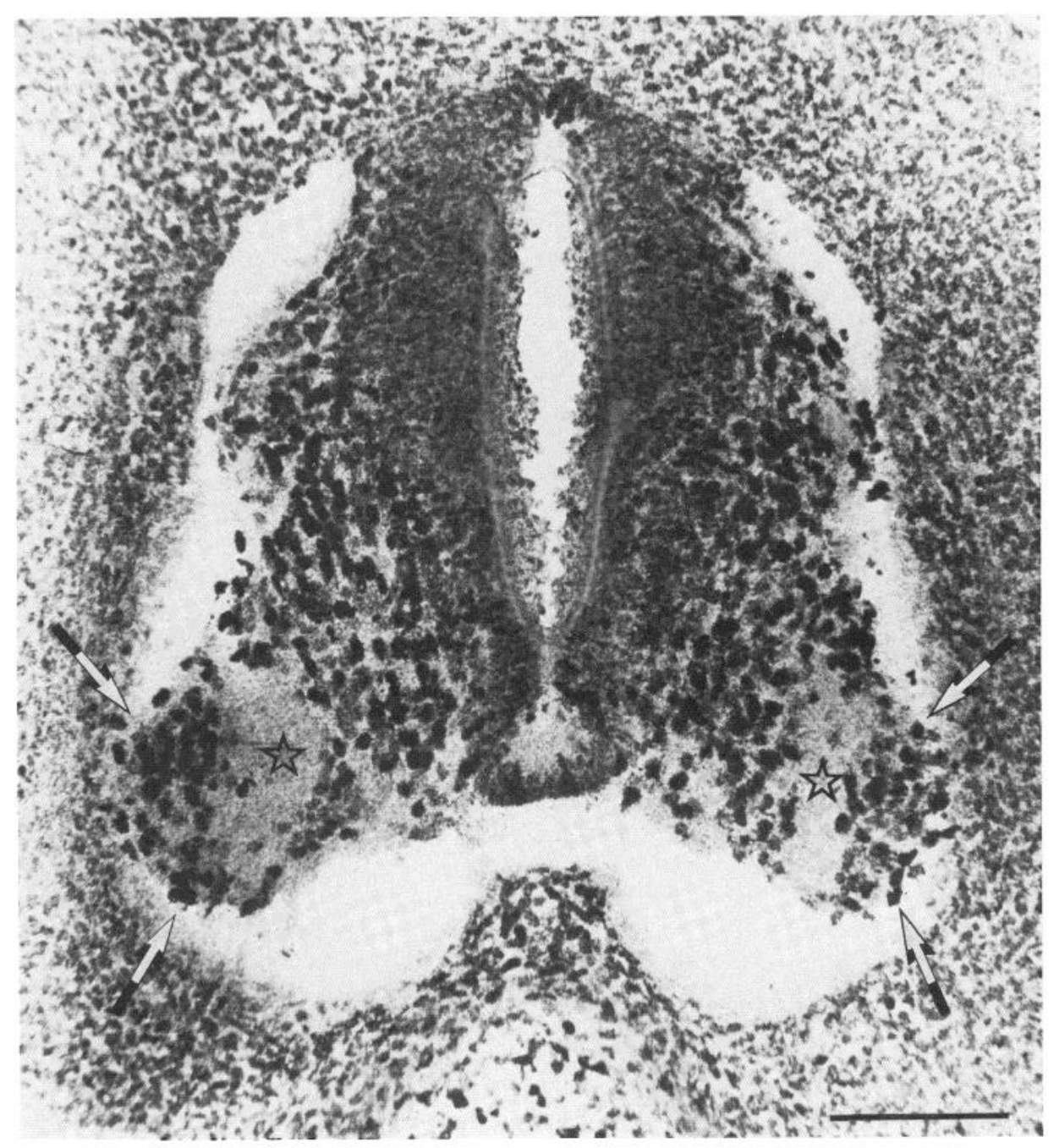

Figure 3. Cross-section of the lumbar lateral motor column of a St 28 embryo form which one leg was removed. This animal received a $\left[{ }^{3} \mathrm{H}\right]$ thymidine injection at $\mathrm{St} 20^{+}$ to $21^{-}$, and the characteristic medial-to-lateral motoneuron birthdate gradients are evident. Regions of labeled (arrows) and unlabeled (stars) motoneurons are noted. Despite the missing limb, the organization of the motor column on both sides appears normal. Calibration bar, $0.1 \mathrm{~mm}$.

(segments 23 to $25 ; N=4$ ), or into the entire lumbar LMC (segments 23 to $30 ; N=3$ ). In five of the seven cases, labeled axons within the calf (see Fig. 5) could be clearly identified as coming from the rostral spinal segments which normally innervate thigh muscles exclusively. Axons projecting to ventral pre-muscle tissue generally penetrated farther into the grafted limb than did axons growing into the dorsal mass. Two of the embryos had received injections of HRP into segments 23 to 25; in the remaining three, all spinal segments had been injected with HRP, but it was possible to trace labeled axons in the grafted calf back to the crural plexus and hence to infer their origin from rostral spinal segments. In all five cases, the crural axons surrounded the calf cartilage in a pattern characteristic of that normally seen around the head of the femur (Fig. 6,top). In the other two embryos examined, labeled axons were seen projecting to fragments of anterior hip and thigh muscle precursor tissue attached to a partial limb girdle and were not seen in the grafted calf. This proximal tissue was not present in the other five embryos studied and is probably related to the absence of a distal projection in these cases.

The fact that axons from rostral spinal segments did not reach the grafted calf in two cases and that neurotization was incomplete in the other five suggests the possibility that cues in the growth path central to the graft may have constrained the distal growth of the motor axons emerging from the crural plexus. Such cues may be as far central as the site of original plexus formation since at this site there is already some bundling of axons destined for particular muscles (Lance-Jones and Landmesser, 1981a); the cues may be associated with fragments of host limb girdle often present in our thighdeleted embryos. Alternatively, either the absence of appropriate pathways into the calf or the presence of other axons in the limb bud coming from the sciatic plexus (see below) might have discouraged axons origi- 

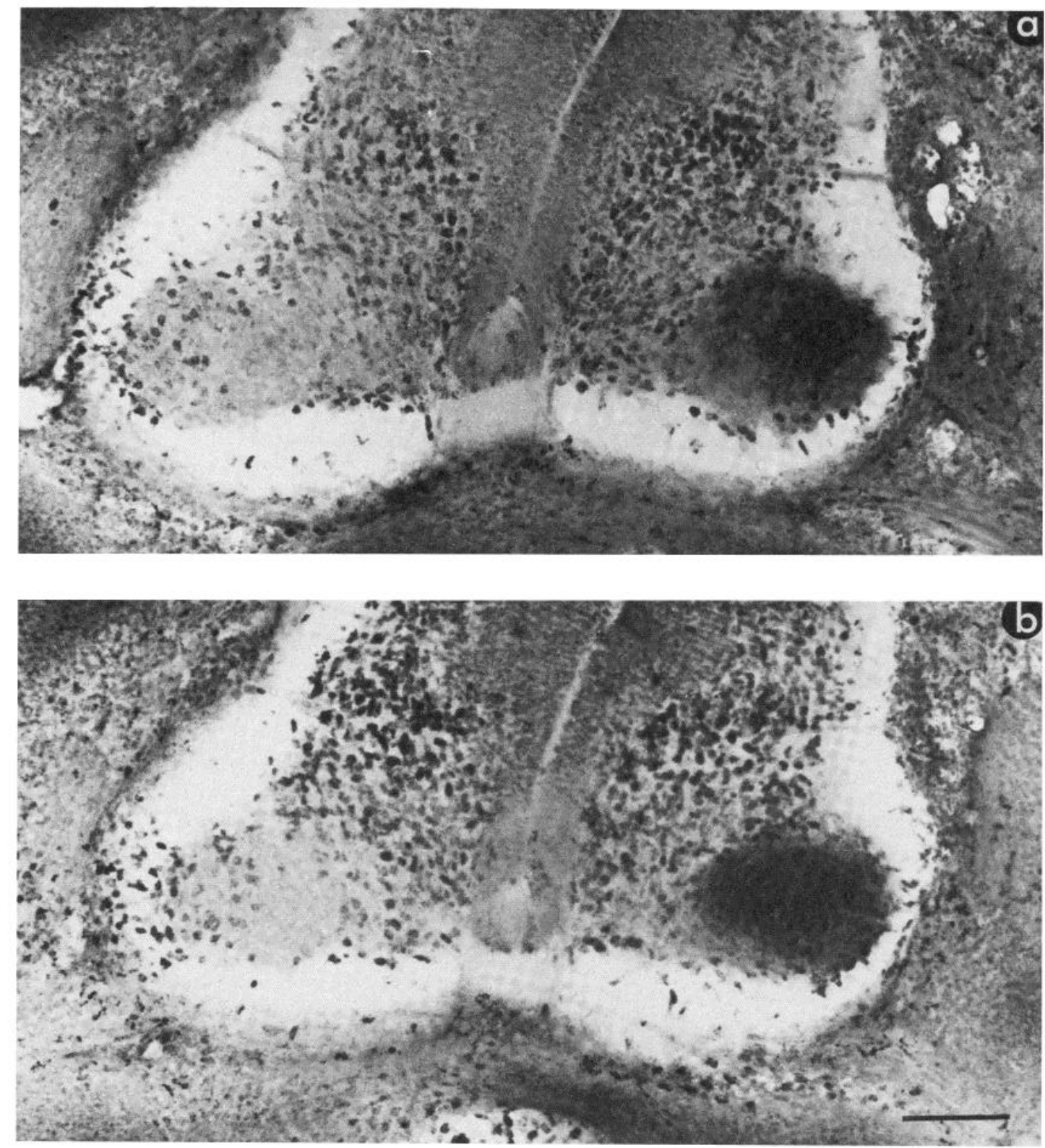

Figure 4. HRP labeling of the lumbar lateral motor column of a St 28 thigh-deleted embryo. Shown are two representative cross-sections from VR $25(a)$ and VR $27(b)$ which are heavily labeled by large injections of HRP into the thigh-deleted limb. There are primarily thigh motor pools at the first of these levels and calf motor pools at the second. The fact that motoneurons throughout the LMC were labeled by peripheral injections indicates that both thigh and calf motoneurons initially sent axons to the thigh-deleted limb. This embryo also received a $\left[{ }^{3} \mathrm{H}\right]$ thymidine injection at $\mathrm{St} 21^{-}$and displays the characteristic labeling pattern within the ventral horn. Calibration bar, $0.1 \mathrm{~mm}$.

nating in anterior spinal cord segments from penetrating the grafted tissue even in the absence of a significant amount of thigh tissue.

In the three embryos in which the entire LMC was injected with HRP, substantial anterograde labeling was seen in the distal calf tissue (Fig. 6, bottom). These axons could be traced back to the sciatic plexus, the plexus through which axons destined for the calf normally enter the limb bud. Other labeled axons remained close to their point of emergence from the sciatic plexus. While we did not identify the subset of sciatic motoneurons sending axons into the distal calf, our reconstructions suggest that calf motor axons were reaching this segment as they do in the normal hindlimb, despite the proximal disturbances of the limb.

In calf-deleted limbs, the question of nerve access is not critical since the normal pathways into the limb were not disrupted by the surgery. The retrograde labeling studies showed that calf axons did in fact grow into the calf-deleted limbs. In these limbs, the question is whether the calf-destined axons actually projected to thigh tissue. In six calf-deleted embryos (St 28), HRP injections were made into caudal spinal cord segments ( 25 to 30 ) to study the projections of axons, a sizable fraction of which normally innervates calf muscles. Labeled axons were found in both nerves projecting to the calf as well as in 


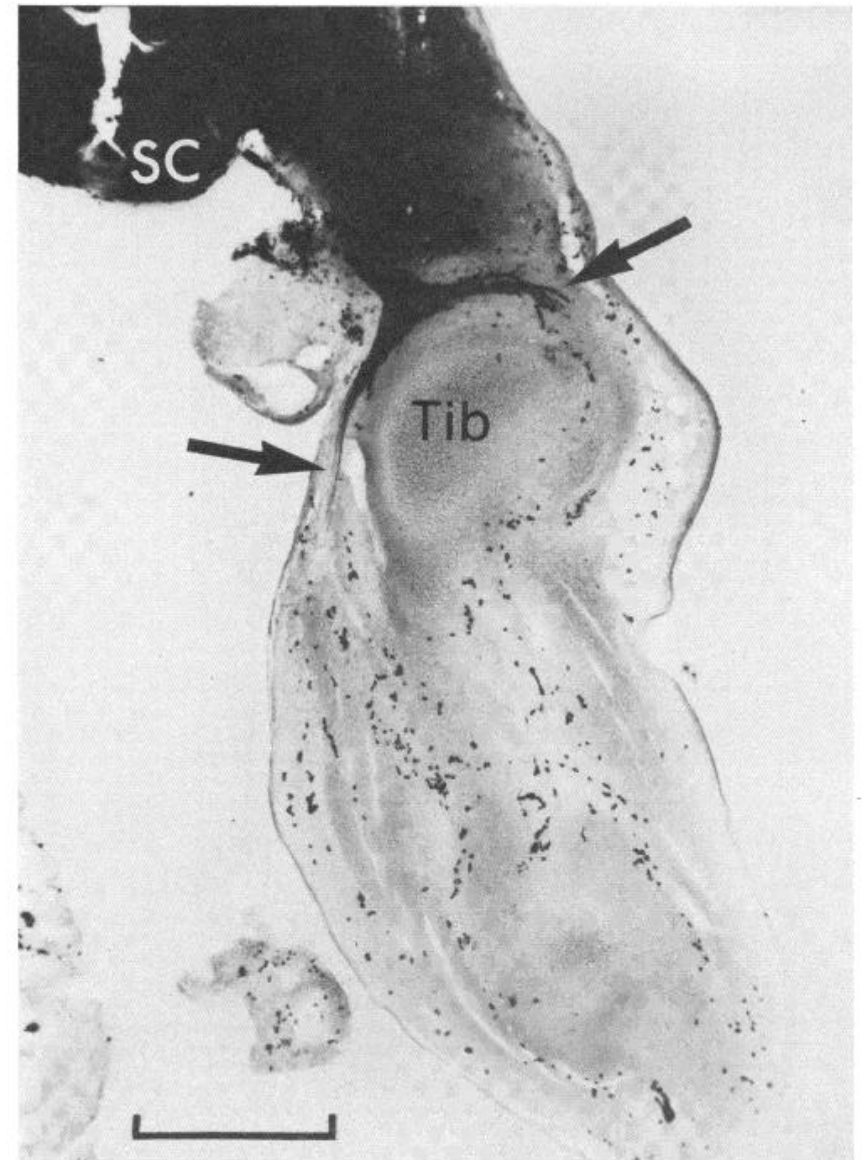

Figure 5. Projections of thigh motoneurons into calf of a St 28-29 thigh-deleted embryo. HRP was injected directly into segments 23 through 25 of the spinal cord (SC), where the enzyme was taken up by motoneurons and transported down their axons into the limb. The axons project as two sheets of nerves around the head of the tibia $(T i b)$, one directed toward ventrally derived calf muscle and the other toward dorsally derived calf muscle (arrows). Note that the thigh axons reach the calf but they do not fully penetrate the calf tissue. Calibration bar, $0.5 \mathrm{~mm}$.

nerves projecting to posterior thigh muscles. This latter finding is to be expected since segments 25 to 30 contain motoneurons which normally innervate both calf and thigh muscles. Many labeled tibial and peroneal axons were observed at the end of the amputated limb, with no apparent termination in muscle tissue. Other labeled tibial and peroneal axons were observed projecting to the distal portions of both the dorsal and ventral muscle mass of the thigh. It is likely that at least some of the ventrally projecting axons were destined for the accessorius muscle and thus could have been normal; distal projections to dorsal muscles are never normally seen in this region. Whether these motoneurons actually made functional synapses on foreign muscles is not known. Clearly, motor axons destined for the calf grew into the thigh tissue despite the absence of their normal target. This indicates that axonal penetration of the limb bud does not require a tropic signal from the limb region in which those axons normally terminate. The reasons why some axons projected to distal thigh muscles and others apparently did not remain to be explained.

\section{After cell death: Selective loss of motor pools and projections of survivors}

Morphology of St 36-38 segment-deleted limbs. The partial limbs used in this study had histologically confirmed deletions of either the thigh bone or the calf and foot bones. Examples of thigh- and calf-deleted limbs stained for cartilage are shown in Figure 7. As was observed in St 28 limbs, there was some variation in the composition and size of the remaining segments, as described below.

In some limbs lacking a thigh, the hip girdle was incomplete. In normal embryos, it consists of three bones (ilium, ischium, and pubis), whereas in some embryos with amputated limbs, only one bone (ilium) was evident. Because the hip girdle was not generally deleted by this operation, some of the femurless legs did contain some thigh muscle. In particular, muscles which normally originate on the hip girdle and insert in the calf (i.e., posterior iliotibialis and iliofibularis) were evident in some "thighdeleted" legs. Also, small atrophic muscles with no apparent tendon or insertion were sometimes associated with the hip girdle. Thus, all thigh-deleted legs by definition lacked femurs. However, they did not necessarily lack all thigh muscles. Nevertheless, each leg represented a considerable deletion of muscles and a disruption of the normal neighbor relationships among those remaining.

In both thigh- and calf-deleted limbs, the size of the remaining segment varied, as did the relative sizes of some of the muscles within it. Serial reconstructions of the legs truncated at the calf, for example, showed considerable variation in the relative size of the iliofibularis (IFB). This muscle normally sends a huge encapsulated tendon into the calf; it is possible that the absence of a calf in some way hindered the development of this muscle. The accessorius (Acc), a muscle which is thought to originate in the calf and then to grow into the thigh (Wortham, 1948), was present in over half of the calfdeleted legs examined. It is not clear whether some of its precursor mesenchyme survived the deletion operation or whether, in this context, the Acc originated in a novel position.

The major muscles in the partial legs were easily identified in serial section reconstructions. Moreover, in most animals that received HRP injections, the injection site was confirmed by morphological criteria: a blood clot and a tear in the appropriate region of the muscle.

Selective cell death among target-deprived motoneurons. After the period of cell death, the motor column serving partially deleted limbs was excessively depleted of motoneurons. The increased cell death did not deplete the motor column uniformly, but rather, selectively. In some cases (e.g., for motor pools in an intermediate position), actual gaps appeared in the LMC where the motor pool for a deleted muscle would normally be located. One such example is shown in Figure 8. In this animal the dorsal thigh muscle, femorotibialis (FT), was missing. The normal motor pool for this muscle is indicated on the control side (on the right side of the figure) with an arrow. A conspicuous gap is evident in the corresponding position on the manipulated (left) side.

Cases like that illustrated in Figure 8 strongly suggested that cell death was selective and corresponded to 


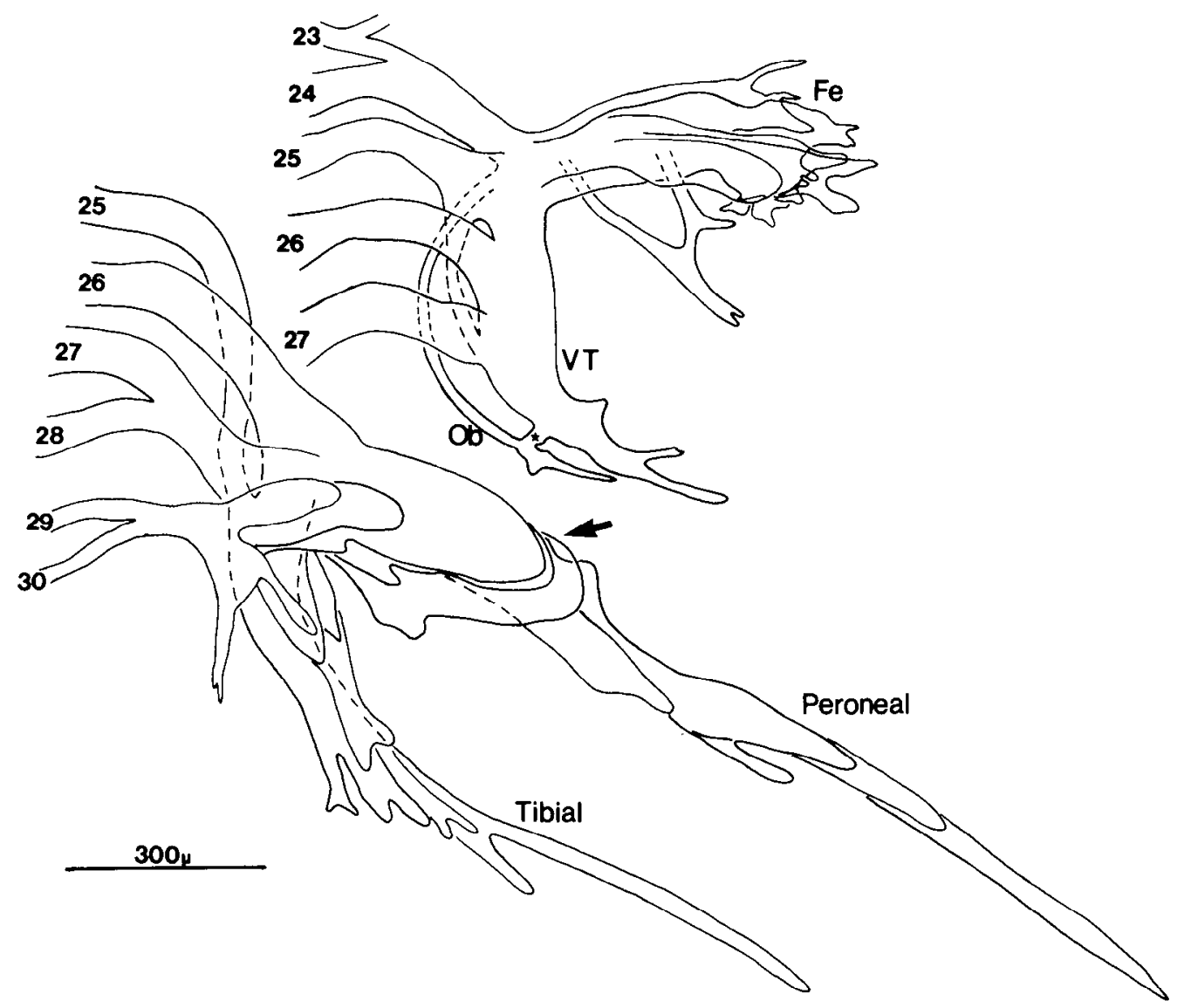

Figure 6. Reconstruction of limb plexuses and innervation pattern of a St 28 embryo lacking a thigh. The top drawing shows the presence of a normal crural plexus and a femoral $(\mathrm{Fe})$ and oburator $(\mathrm{Ob})$ nerve by axons in segments 23 to 25 growing into the anterior portion of the grafted calf. It also illustrates the growth of axons from segments 25 to 27 into the proximal ventral portion of the grafted calf as if it were ventral thigh tissue $(V T)$. Some axons from this sheet join with axons leaving the crural plexus via the obturator nerve; this aberrant pathway is indicated by a star. All of the axons in the anterior part of the grafted calf came into close proximity with calf muscle precursor tissue but failed to innervate it. The bottom drawing shows the formation of a normal sciatic plexus by axons in segments 25 to 30 . The peroneal and tibial nerves emerged normally from the plexus and grew into the calf tissue. Note that a large volume of axons remain far proximal in the graft, close to the sciatic plexus (arrow). Both crural and sciatic plexuses formed around the proximal head of a fused tibia/fibula; the cartilage elements were distinct farther distal in the grafted calf. A remnant of the host's ischium was presented in this embryo.

missing limb muscles. However, because the relative positions of motoneurons within the LMC could have been changed by motoneuron loss, we verified our identification of motoneurons using autoradiography. In 11 embryos (5 calf deletions; 6 thigh deletions) that had received $\left[{ }^{3} \mathrm{H}\right]$ thymidine approximately halfway through the period of motoneuron birthdates (St 201/2), there was a consistent correlation between the presence or absence of labeled (i.e., thigh) or unlabeled (i.e., calf) motor pools and the presence or absence of those segments in the limb.

Figure 9 shows a comparison between the normal and experimental motor columns of a St 37 embryo lacking a calf. Several cross-sections taken between VR 24 and 29 are shown. In the rostral segments, in which there are only thigh motor pools, the two sides of the ventral horn are close to the same size. A notable size disparity emerges, however, around VR 26, in which many of the motor pools normally supply calf muscles. On the control side, the large, unlabeled medial cluster is evident, whereas on the calf-deleted side, it is not. The remaining motoneurons on the manipulated side are labeled, corresponding to the laterally labeled thigh motor pools on the control side. Thus, with respect to the mediolateral axis (as evident in each cross-section in Fig. 9) as well as the rostrocaudal axis (as evident in the series of crosssections), a pronounced selectivity in the depletion of motor pools is apparent. When calf muscles are missing, so are calf motor pools.

Similarly, in thigh-deleted limbs, there was a depletion of the motor pools normally supplying thigh muscles. A selective depletion of labeled or unlabeled motoneurons in animals lacking thighs or calves, respectively, was seen consistently in all 11 embryos which had been given $\left[{ }^{3} \mathrm{H}\right]$ thymidine at the appropriate stage.

The autoradiographic data demonstrate what was seen consistently in the spinal cords of animals with partial limbs; namely, the selective depletion of target-deprived motoneurons. Moreover, subject to this increased cell death, the LMC did not seem to substantially reorganize the position of its remaining pools.

In addition to the evident depletion of target-deprived 

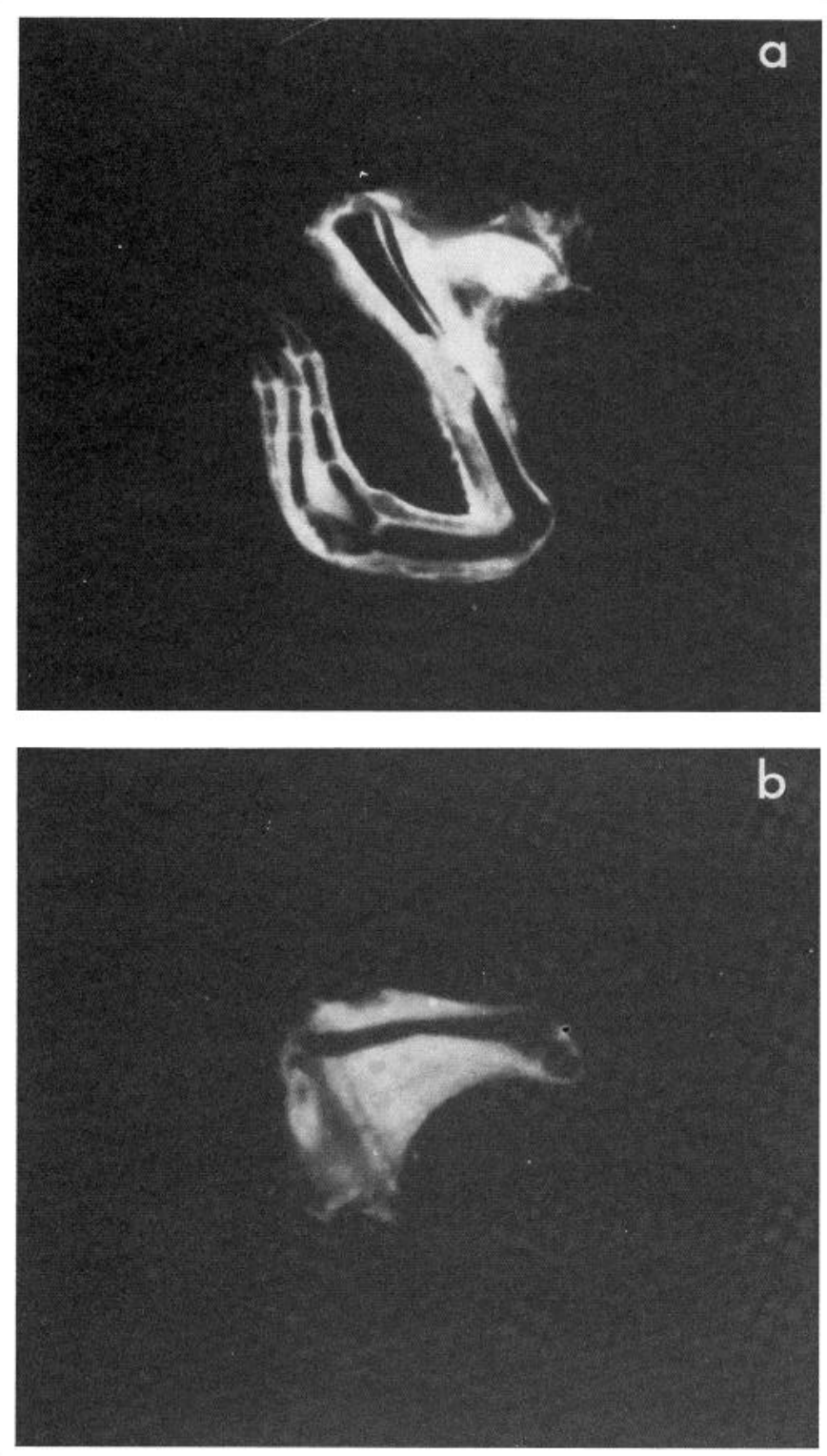

Figure 7. Whole mount segment-deleted limbs stained for cartilage. $a$, Thigh-deleted leg from a St 37 embryo; $b$, calfdeleted leg from a St 36 embryo.

motor pools in thigh- and calf-deleted animals, there was an observed, albeit unquantified, correlation between the size of a muscle present, relative to its normal size, and the size of its motor pool, relative to the pool's normal size. In several of the femurless animals, there were a few thigh muscles which were greatly reduced relative to their normal sizes. The motor pools which normally serve these muscles were also much smaller than usual. Likewise, the calf muscles were rarely as large as those in calves in normal embryos and their motor pools were visibly smaller than normal.

The motor projection to partially deleted limbs. In addition to the selective cell death among target-deprived motoneurons, there was a selective projection of the remaining motoneurons to their normal targets, as assessed by HRP injections. Motor pools were mapped in 30 embryos with partial limbs. Specific HRP injections were made into six muscles or groups of muscles in the thigh- or calf-depleted limbs. In embryos lacking a thigh, either dorsal or ventral calf muscles were injected as a group. In embryos lacking both calf and foot, four muscles or muscle groups were injected: (1) posterior iliotibialis/ iliofibularis (PIT/IFB), (2) femorotibialis (FT), (3) adductor (AD), and (4) flexorius (caudilioflexorius, CFx, and ischioflexorius, IFx) muscles. The consistent result in each case was that the vast majority of HRP-labeled motoneurons were in a region of the motor column which normally serves the muscle injected.

A sample reconstruction of the lumbar LMC from an animal lacking a thigh is shown in Figure 10. HRP was injected into the ventral calf muscles of the thigh-deleted limb. The shaded motor pools on the right-hand side of the spinal cord (as viewed by the reader) indicate the normal location of motoneurons serving the injected muscles, as taken from the normal motor pool map (see Fig. 2; Hollyday, 1980). HRP-labeled cells are found in a corresponding position on the experimental side. Although the size of the limb differs on the two sides, both the HRP-labeled neurons and the unlabeled medial cluster on the control side are the same distance away from the central canal. The partially depleted LMC does not extend as far laterally, however, as does the normal LMC. This is due to the selective depletion of the laterally lying thigh motor pools described above.

HRP injections were also made into dorsal calf muscles in embryos lacking a thigh. In these embryos, labeled motoneurons were found in intermediate positions (i.e., between a medial pool and a lateral pool) in the caudal half of the LMC. Motor pools in these positions normally serve dorsal calf muscles.

The results from all 11 thigh-deleted embryos injected ( 5 ventral calf, 6 dorsal calf) are summarized in Table I. For each injection type, the total number of labeled cells in each case as well as the total percentage of labeled cells lying within the region appropriate for the normal motor pools is listed. In addition, the distribution of label is schematized on a rectangular grid in which the rostrocaudal and mediolateral axes of the LMC are represented. The rostrocaudal axis is shown horizontally and is demarcated by ventral root numbers. The mediolateral axis is shown vertically and is divided into three regions: medial (M), intermediate (I), and lateral (L). "Medial" motor pools are those to the left of the dashed line in Figure 2. They innervate ventrally derived muscles. "Intermediate" and "lateral" pools are to the right of the dashed line in Figure 2 and innervate dorsally derived muscles. The averaged percentage of HRP-labeled cells in each position is noted in Table I (a blank square indicates no labeled cells in that region). The regions which correspond to the normal motor pools for the injected muscles are indicated in the table with heavy lines.

For both injection types, nearly all of the labeled cells are found in regions appropriate for the normal motor pools. The largest HRP injections of the dorsal calf labeled some cells in the medial cluster, which normally serves ventral calf muscle. It is likely that this resulted from HRP leakage to the ventrally derived muscle, medial gastrocnemius, which overlies dorsal calf muscle in 


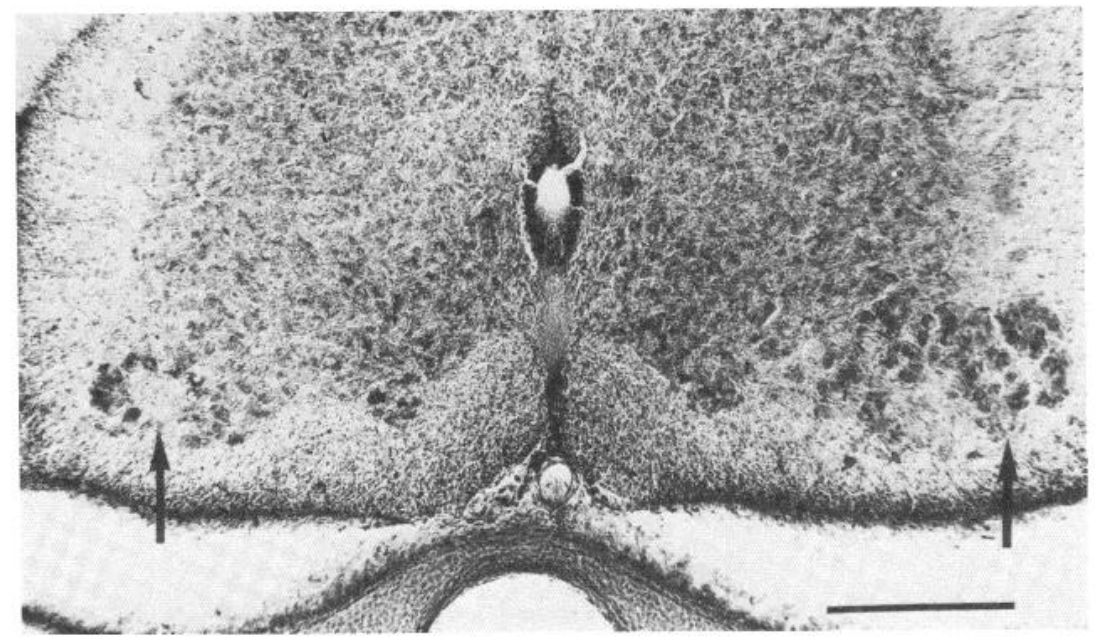

Figure 8. Depletion of a motor pool which would normally serve a muscle which was deleted. Cross-section is of a St 38 thigh-deleted embryo which was missing the muscle, femorotibialis. The normal motor pool for this muscle is indicated on the control side (shown on the right) of the motor column with an arrow. A conspicuous gap in the corresponding position is evident on the experimental side (on the left), also indicated with an arrow. The motor pools supplying the remaining but smaller than normal thigh muscles (e.g., adductor and iliotibialis) are quantitatively depleted but not absent. Calibration bar, $0.2 \mathrm{~mm}$.

the proximal calf. None of the HRP label was found in normal thigh motor pool regions.

In one thigh-deleted (femurless) embryo, HRP was injected not into calf muscle but rather into the most proximal, dorsolateral muscles originating on the hip girdle. Reconstructions of other femurless embryos had revealed the occasional presence of the muscles PIT and IFB in this region; a reconstruction of this leg confirmed the presence of and injection site into these muscles. These were virtually the only thigh muscles present in the limb; their motor pools were virtually the only thigh motor pools present in the corresponding LMC. In this case, label was found in the thigh motor pools which normally supply the PIT and IFB. These muscles, like the muscles of the calf, were innervated by their normal motor pools even when their normal neighbor muscles were absent.

Similar selectivity in motor innervation was also found in animals lacking a calf and foot. Localized HRP injections were made into thigh muscles of 19 calf-deleted embryos. A typical reconstruction from one of the cases is shown in Figure 11. In This embryo, the thigh muscle PIT was injected. Its normal motor pool position is shown in shading on one side of the spinal cord; labeled motoneurons are in a corresponding position on the experimental side, in the sense that they are in the lateralmost cluster. Although the extensive depletion of motoneurons at the caudal level makes a positional designation of motor pools somewhat ambiguous, the autoradiographic data presented earlier showed that the motor pools surviving cell death (in animals with partial limbs) were composed of their normal subset of motoneurons as determined by their characteristic birthdates. Thus, the labeled cells in Figure 11 are called "lateral" in view of what must have been their pre-cell death relative position. They could also be called "late-born."

The results from all of the injections of embryos lacking a calf and foot are summarized in Table II. Four classes of injections are listed, as well as the number of cases and total number of labeled cells in each class. The distribution of labeled cells is schematized as in Table I.

As is evident in Table II, the first two classes of injections (PIT/IFB and FT) resulted in a very high percentage of labeled cells in the normal motor pools for those muscles. The percentage was somewhat lower for $\mathrm{AD}$ injections; however, it should be pointed out that two of the four embryos in which the AD's motor pool was mapped received very large injections of HRP (more than 600 labeled cells per case) which likely filled AD's neighboring muscles as well. AD's neighbors include the flexorius muscles whose normal motor pool regions are shown in the last section of Table II. It is apparent that most of the labeled cells outside of AD's normal motor pool region are in positions appropriate for serving one of the flexorius muscles. The smaller injections of $\mathrm{AD}$ exclusively labeled cells in the region of its normal motor pool.

The final class of HRP injections as listed in Table II was into muscles derived from the flexorius muscle mass. This ventral mass normally gives rise to two thigh muscles, CFx and IFx, and one calf muscle, flexor digitorum longus (FDL) (Romer, 1927). This latter muscle could not be identified in any of the calf-deleted limbs examined. Both large and small injections were made into either one or both of the thigh flexorius muscles. Some filling of the thigh muscle Acc was also anticipated, as this muscle inserts onto the CFx.

As is evident in Table II, most of the resultant label in 

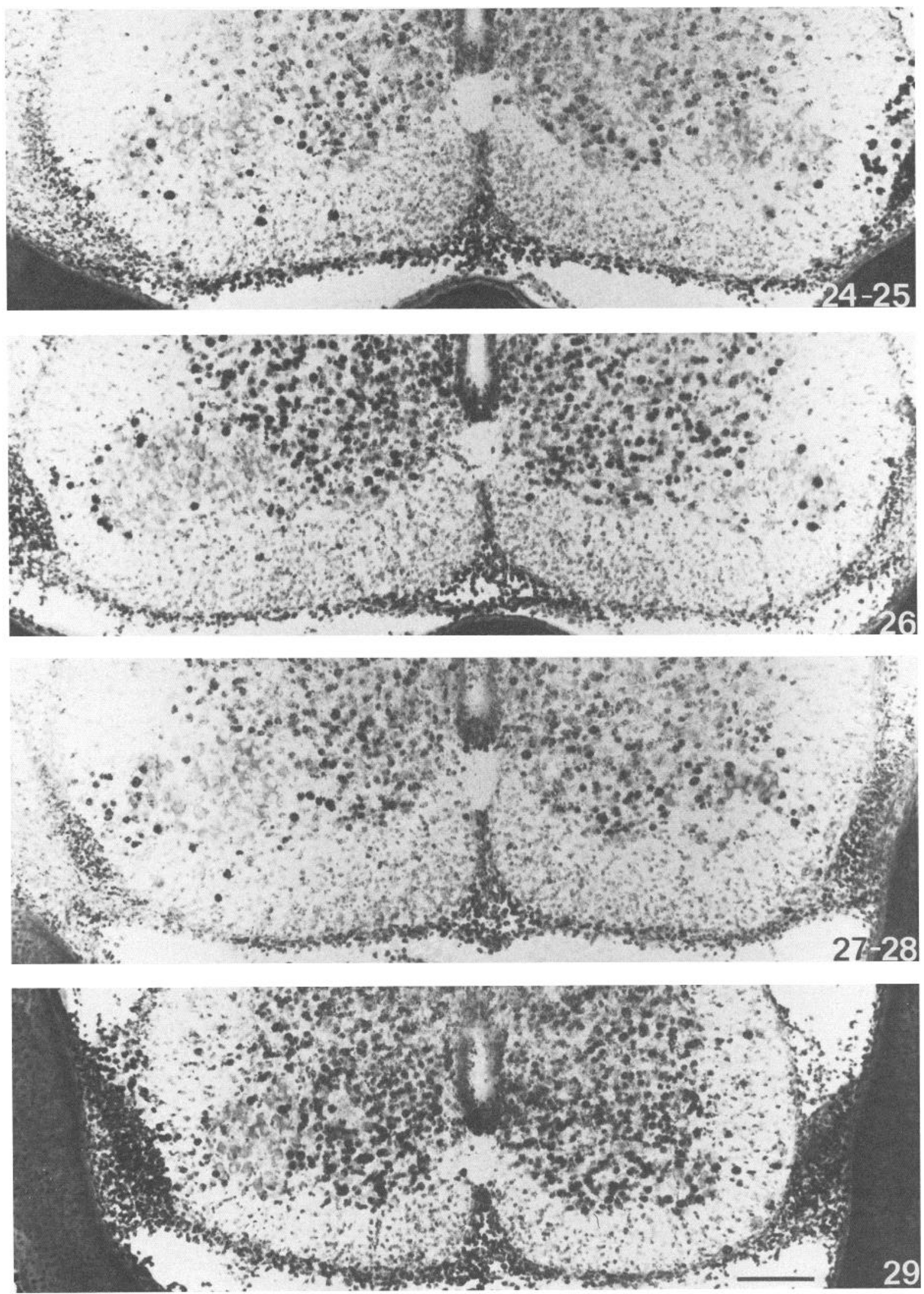

Figure 9. Motoneuron depletion in the lateral motor column of a St 37 calf-deleted embryo. The embryo received a $\left[{ }^{3} \mathrm{H}\right]$ thymidine injection at St 21 which labeled roughly the lateral third of the motor column. Ventral root numbers are indicated to the lower right of each cross-section. At the rostral end of the motor column (VR 24-25), where there are thigh motor pools, the two sides of the spinal cord are roughly symmetric. A size disparity emerges, however, around VR 26-27, where there are primarily calf-serving motor pools. The large unlabeled medial cluster of calf motoneurons which is present on the control side (to the left as viewed by the reader) is depleted on the calf-deleted side. What cells remain on the manipulated side are largely ${ }^{3} \mathrm{H}$-labeled, indicating that they would normally be thigh motoneurons (see Fig. 2). Calibration bar, $0.1 \mathrm{~mm}$. 


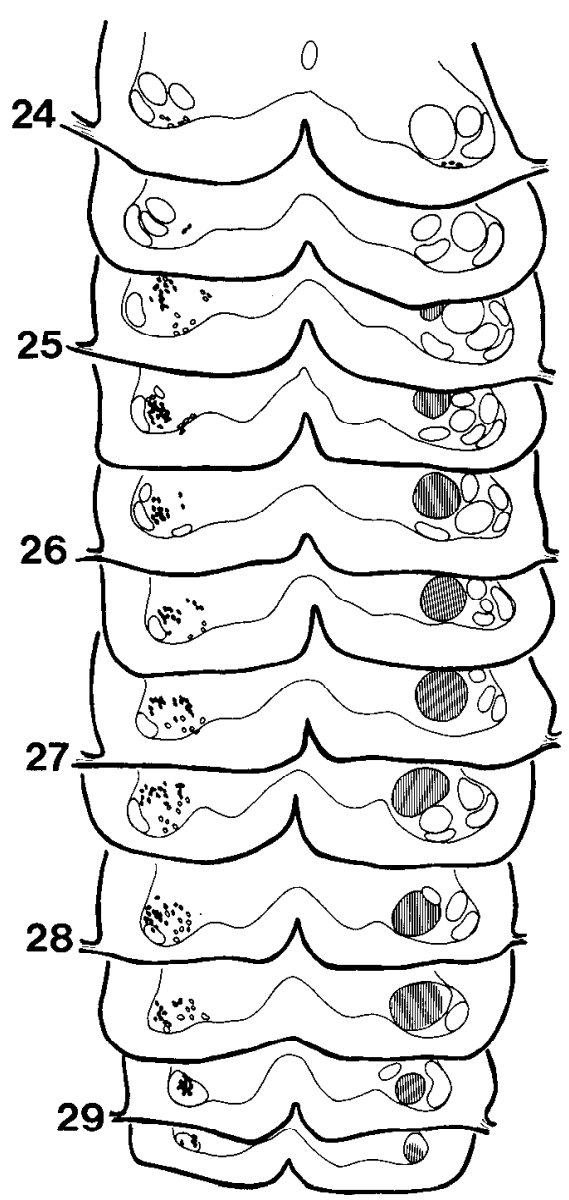

Figure 10. Reconstruction of the distribution of labeled cells following an HRP injection of ventral calf mass in a thighdeleted limb. The normal motor pools for the muscles injected are shaded on the control side (to the right as viewed by the reader). Labeled cells are in the corresponding position on the experimental side. The lateralmost thigh-serving motor pools are missing at the caudal levels. these cases was confined to the normal pool regions for the IFx and CFx (shown by dark lines). There were also a few labeled cells around VR 27 which could have resulted from HRP filling of the Acc, whose motor pool

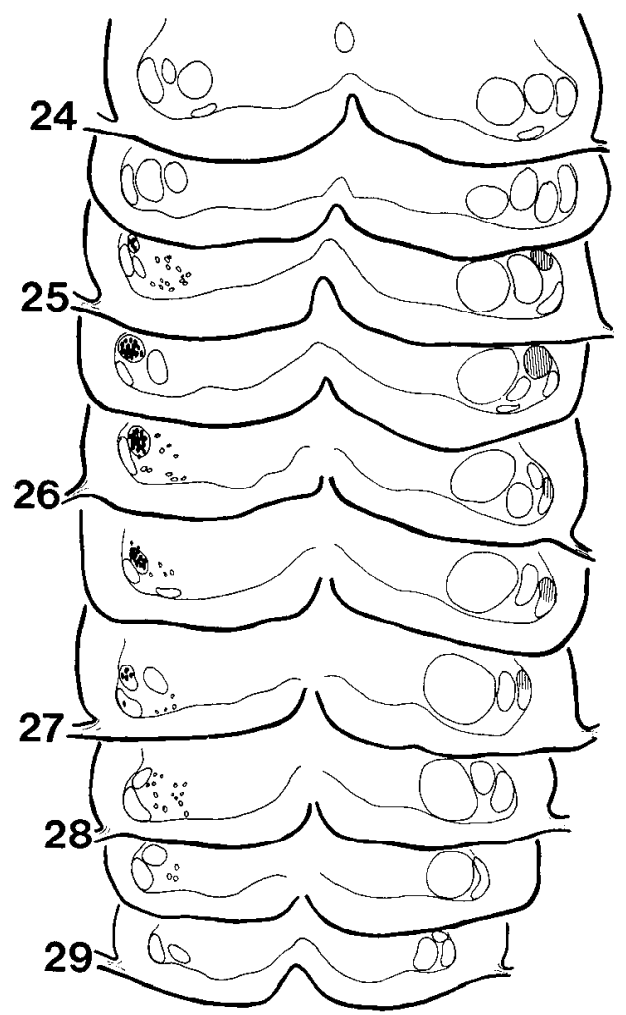

Figure 11. Reconstruction of the distribution of labeled cells following an HRP injection in the PIT of a calf-deleted limb. The normal motor pool for this muscle is shaded on the control side. Labeled cells are in the corresponding position on the experimental side. The medial cluster of calf-serving motoneurons is greatly depleted on the experimental side at caudal levels.

TABLE I

Distribution and averaged percentages of labeled cells in thigh-deleted embryos following HRP injections of calf muscles ${ }^{a}$

\begin{tabular}{|c|c|c|c|c|c|c|c|c|c|c|c|c|}
\hline \multirow{2}{*}{$\begin{array}{c}\text { muscle } \\
\text { yroup } \\
\text { injected }\end{array}$} & \multirow{2}{*}{$\begin{array}{l}\text { number } \\
\text { of } \\
\text { cases }\end{array}$} & \multirow{2}{*}{$\begin{array}{l}\text { number of } \\
\text { labeled } \\
\text { cells/case }\end{array}$} & \multirow{2}{*}{$\begin{array}{l}\text { average } \\
\text { number of } \\
\text { labeled } \\
\text { cells/case }\end{array}$} & & \multicolumn{7}{|c|}{ distribution of labeled cells } & \multirow{2}{*}{$\begin{array}{l}\text { percent in } \\
\text { normal } \\
\text { motor pool } \\
\text { region }\end{array}$} \\
\hline & & & & Dosition & 23 & 24 & 252 & $6 \quad 2$ & & 82 & 30 & \\
\hline \multirow{4}{*}{$\begin{array}{c}\text { ventral } \\
\text { calf }\end{array}$} & \multirow{4}{*}{5} & \multirow{4}{*}{$\begin{array}{r}44 \\
88 \\
322 \\
383 \\
671\end{array}$} & \multirow{4}{*}{322} & M & & & 9.4 & 18.2 & 33.0 & 29.6 & 5.6 & \multirow{4}{*}{98.5} \\
\hline & & & & I & & & .2 & 1.2 & 2.4 & .4 & & \\
\hline & & & & L & & & & & & & & \\
\hline & & & & & & & & & & & & \\
\hline \multirow{5}{*}{$\begin{array}{l}\text { dorsal } \\
\text { calf }\end{array}$} & \multirow{5}{*}{6} & \multirow{5}{*}{$\begin{array}{r}36 \\
82 \\
84 \\
219\end{array}$} & \multirow{5}{*}{177} & M & & & 1.6 & 4.4 & 5.4 & 1.1 & .5 & \multirow{5}{*}{87.0} \\
\hline & & & & I & & & 16.4 & 31.1 & 34.0 & 5.5 & & \\
\hline & & & & L & & & & & & & & \\
\hline & & & & & & & & & & & & \\
\hline & & & & & & & & & & & & \\
\hline
\end{tabular}

${ }^{a}$ Heavy lines indicate the positions of motor pools innervating ventral (top) and dorsal (bottom) calf muscles in normal animals. M, medial; I, intermediate; L, lateral. 
TABLE II

Distribution and averaged percentages of labeled cells in calf deleted embryos following HRP injections of thigh muscles ${ }^{n}$

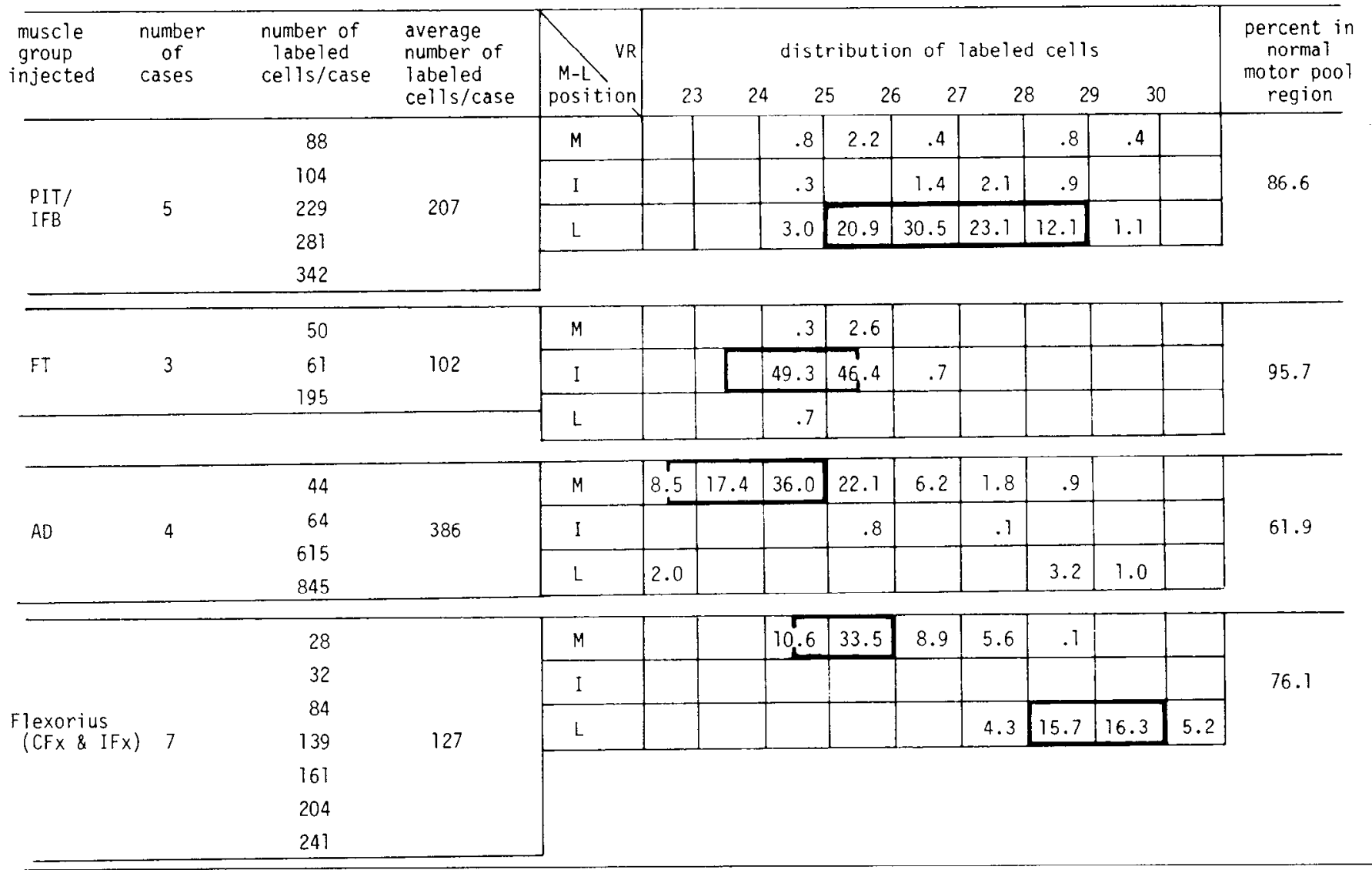

${ }^{a}$ Heavy lines in each table indicate the position of motor pools in normal animals. M, medial; I, intermediate; L, lateral.

is in this region. Alternatively, it could reflect mis-innervation on the part of a few motoneurons which would normally have innervated the missing flexorius muscle, FDL (whose motor pool is also in this region). Thus, with the possible exception of a small contribution from either the FDL's or the ACC's motor pool, the results indicate that the two thigh muscles were served exclusively by their normal motor pools.

The HRP labeling results indicate that surviving motoneurons innervate their normal muscles. The only uncertainty in this conclusion is the previously mentioned possibility that motoneuron identification based on spinal cord location could be misleading because of distortions in morphology. To address this possibility, several embryos were doubly injected; that is, they received $\left[{ }^{3} \mathrm{H}\right]$ thymidine at stage $20^{1 / 2}$ and $\mathrm{HRP}$ at St 38 . In all eight such cases the HRP-labeled motor pools were appropriately labeled or unlabeled by ${ }^{3} \mathrm{H}$. For example, in several doubly injected calf-deleted embryos, the motor pool for the thigh muscle CFx was mapped. Consistent with its far lateral position, the CFx motor pool is normally late-born. Not only were the HRP-labeled cells in a region which normally serves the $\mathrm{CFx}$, but they were also appropriately labeled by the $\left[{ }^{3} \mathrm{H}\right]$ thymidine injection.

Neural pathways in segment-deleted limbs. Serial reconstructions of the peripheral branching patterns of nerves showed the innervation pattern in manipulated limbs to be normal with respect to the muscles present. For example, in nearly all (13 of 15) of the thigh-deleted limbs examined at St 36-38, there was only one nerve entry point into the limb: the sciatic foramen. All calf and foot muscles and several thigh muscles are normally supplied via this pathway. The obturator nerve was observed in two femurless legs, both of which contained the normal thigh targets of these nerves (i.e., the $\mathrm{AD}$ muscle). Neither the femoral nerve nor its normal targets were present in thigh-deleted limbs.

Once into the thigh-deleted limb, nerves followed their usual pathways relative to the muscle environment. If the IFB was present, the sciatic nerve was medial to it, as it is normally. The tibial and peroneal nerves diverged to opposite sides of the calf, as they do in normal calves. The branching patterns were identical to those of normal animals except for the absence of nerves associated with the absence of specific muscles. In animals which had a full complement of calf muscles, the nerve-branching patterns and sites of muscle innervation were identical with normal calf innervation.

Similarly, in calf-deleted limbs, nerve reconstructions indicated that the foramina, pathways, and branching patterns were entirely thigh-like. There were fewer nerve bundles than usual which entered the limb at the sciatic foramen, which is consistent with the fact that nerves destined for the calf and foot (as well as the thigh) usually enter there. The characteristic branches of the sciatic 
nerve which innervate the posterior thigh muscles were observed. The pathway divergence of the calf-destined peroneal and tibial nerves which is normally seen in the mature innervation pattern was not observed. There were often nerves in the distal part of the thigh; however, their course toward the limb surface suggested that they were sensory, rather than motor.

\section{Discussion}

Animals with surgically created partial limbs showed selective depletion of motor pools whose normal targets were missing and selective innervation of remaining muscles by their normal motor pools. Before the period of cell death, the entire motor column projected to the partial limb buds via the crural and sciatic plexuses. After cell death, however, only the normal pools remained and these projected to their normal targets. There was no compression of the entire motor column into the partial limb. These findings are consistent with the electrophysiological studies on truncated chick wings by Bennett et al. (1979), which showed that the relative segmental contribution to muscles of the remaining limb segments was essentially normal. However, their electrophysiological technique was not appropriate for determining the size or location of motor pools innervating the remaining muscles or the fate of target-deprived motoneurons.

The results of our deletion experiments demonstrate the selective innervation of muscles in partial limbs. When thigh and calf motor axons jointly invaded the thigh of a calf-deleted leg, only the thigh motoneurons successfully innervated it. The calf motoneurons largely died. Just the reverse was observed in thigh deletions. Hence, when both thigh and calf motoneurons invaded a limb segment, only the normal motor pools for the muscles present survived. Furthermore, despite gross disturbances in the positions of muscle precursor tissue relative to the outgrowing axons, the surviving motoneurons innervated their normal targets.

Projections of surviving motoneurons. Our findings in thigh-deleted and calf-deleted limbs are difficult to explain without positing differences between thigh and calf motoneurons which account for their differential behavior as demonstrated by their characteristic initial growth trajectories and their later pattern of selective termination within the limb. It is not possible to attribute our findings to a model of limb innervation that patterns connections between motoneurons and limb muscles according to a carefully timed sequence of axon arrival at undifferentiated targets or by the maintenance of fiber neighbor relationships. Both of these hypotheses would predict that the same subset of motor axons that innervates thighs in calf-deleted limbs would also innervate calves in thigh-deleted limbs. This subset would be composed of either the earliest arriving axons or those in such a position as to branch first from the main nerve trunks. Since this was not observed, we conclude that there are growth cues associated with the limb which apparently guide different subsets of axons to different regions of the limb bud. The motor axons themselves must be distinguished for them to respond differently to these cues. Motoneuron differences may well depend on their age or position within the motor column, which themselves are not unrelated attributes.
Selective cell death. Previous studies on partially amputated limbs (Hamburger, 1934) showed an increased amount of cell death in the corresponding motor column. The thigh and calf deletion studies reported here showed this increased cell death to be a selective process; in particular, increased cell death was observed in targetdeprived motor pools. This is consistent with what is seen in Xenopus tadpoles with partial limbs. Lamb (1981) found that partial amputations of the hindlimb resulted in increased cell death in the motor column, and the distribution of motoneuron survivors was in a general way appropriate for the remaining segments. Our results are somewhat more detailed since, unlike in Xenopus, individual motor pools in the chick are recognizable as histologically distinct motoneuron clusters and are spatially discrete. Our use of $\left[{ }^{3} \mathrm{H}\right]$ thymidine autoradiography to confirm motor pool identity by birthdate strengthens our conclusions regarding the selectivity of neuron survival and loss. These findings are also consistent with the previous anatomical studies of Stirling and Summerbell (1977), which demonstrated that the peripheral nervebranching patterns in truncated chick wings were appropriate for the remaining limb segment. In that study, as well as our own, it was found that where a muscle was missing, so was the peripheral nerve which normally served it. The present study further showed that the target-deprived motoneurons themselves were missing from the motor column.

We also observed increased cell death in motor pools serving muscles which were present in partial limbs, but at reduced size. Our surgical manipulations could have disturbed axonal ingrowth in some embryos, resulting in reduced motor projections to some muscles; in these cases, muscle atrophy would be a consequence of insufficient motor innervation. Another explanation, however, is that the surgical manipulations left or transferred varying amounts of muscle precursor tissue and that where muscles developed smaller than usual, they required or supported innervation from only a fraction of their normal motor pool.

Our experiments on the innervation of partial limbs before cell death showed that all of the motor axons projected to the partial limbs just as they do in normal embryos (Chu-Wang and Oppenheim, 1978), although only a portion of the motor axons actually appeared to have complete access to the reduced amount of muscle precursor tissue. It seems unlikely that the selective motoneuronal death we observed can be explained simply as a consequence of motoneurons reaching unexpected or incorrect targets, since it has been shown in a number of experimental circumstances that motoneurons innervating abnormal targets do not necessarily die (Hollyday et al., 1977; Hollyday, 1981; Lance-Jones and Landmesser, 1981b; Summerbell and Stirling, 1981). Additional examples are reported in the two following papers (Whitelaw and Hollyday, 1983a, b). The fact that the incorrectly terminating motoneurons do not die indicates that failure to reach their normal target is not a sufficient explanation for cell death.

The explanation for the selective cell death seen in these experiments seems to be that certain motoneurons are prevented from making effective synapses with abnormal target muscles. There are several possible reasons 
why synapse formation might be prevented under these experimental circumstances. One possibility is that pathway cues at the base of the limb bud result in the channeling of axons destined for various thigh and calf muscles such that motor axons become irreversibly committed to a pathway which guides them to a part of the developing limb bud where no muscle develops, and hence they die because of the absence of any target whatsoever. While our material suggests that early guidance cues are important for channeling axons into particular parts of the limb, we doubt that this channeling is so restrictive as to preclude motoneurons in the present circumstances from coming into contact with any target whatsoever. In many St 28 embryos, we observed nerves abutting muscle precursor tissue which they subsequently failed to innervate (see Figs. 5 and 6). In these cases it is difficult to argue that axons lacked access to the muscle tissue, although we recognize that "access" may be more than the absence of obvious barriers to axonal growth. In addition, motoneurons have been shown to reach muscles by clearly aberrant or novel pathways both in the present study (see, for example, Fig. 6) and in a variety of other experimental circumstances (Hollyday, 1981; Lance-Jones and Landmesser, 1981b).

A second possibility is that a combination of the normal pathway guidance cues and the normal timing of axon outgrowth results in motoneurons reaching their normal muscles prior to the arrival of abnormal motoneurons. This might result in some change in the innervated muscle so as to prevent abnormal motoneurons from reaching it or from forming effective synapses in it. One might imagine that innervation of a muscle could terminate the release of an attracting substance, or it could stimulate the production of an inhibitory signal indicating that a particular muscle is unavailable for innervation. This possibility also seems unlikely since, in order for it to explain our findings, one must assume that the appropriate motor axons reach the available muscle precursor tissue before abnormal ones in both thighdeleted and calf-deleted situations, despite the substantial and different disruptions in the growth paths in these two types of limbs.

A third possibility is that the difference between motoneurons, previously discussed in connection with the normal termination of surviving motoneurons, places the normal motoneurons at a competitive advantage to abnormal motoneurons in successfully innervating particular muscles. Such interactions could take place in the process of synaptogenesis (Sperry and Arora, 1965; Dennis and Yip, 1978). Alternatively, such interactions may take place at earlier choice points in the outgrowth pathways; this may help to account for the partial neurotization of segments by abnormal motoneurons that we observed in embryos lacking thighs.

While it is not possible to conclude from the present evidence that any one of these suggestions is a complete explanation for the selective cell death that we observed, it seems likely to us that some form of competitive interaction is at least a part of the underlying process. The question of competitive interactions in limb innervation has been addressed previously in the context of whether motoneurons will expand their termination sites in the absence of motoneurons destined to innervate particular muscles (Lance-Jones and Landmesser, 1980). The fact that they seem not to and the fact that the inilial outgrowth of motoneurons is relatively specific (Landmesser and Morris, 1975; Landmesser, 1978b; Lance-Jones and Landmesser, 1981a) clearly indicates that normal limb innervation does not result from totally random motoneuron outgrowth and the subsequent retraction of axons based on competitive interactions. The present situation differs in that the question is the fate of motoneurons lacking a target under experimental conditions in which a normal complement of motoneurons is available for all possible targets. The issue of whether motoneurons reaching an inappropriate target are in fact excluded if the full numerical complement of motoneurons is present has not been approached experimentally in the chick.

It may also be relevant that prior experiments on the effects of absence of motoneurons involved deletions of anterior spinal cord segments; the muscles tested were those normally supplied by axons which aggregate into fascicles quite centrally, take distinct pathways into the limb, and innervate fairly disjoint subsets of limb muscles (Lance-Jones and Landmesser, 1981a). The apparent lack of competition in this circumstances may reflect a far proximal commitment on the part of different motor axons to different constraining pathways. The failure to observe a competitive interaction between motoneurons in separate pathways does not rule out the possibility of competition among axons within a common neural pathway in normal development, nor does it preclude the interpretation that competitive interactions between axons normally in different pathways occur in particular experimentally perturbed situations. In the partial limb experiments reported here, there is both an abundance of nerves relative to the remaining muscle tissue and a possible interaction of axons normally destined for different targets. In partial limbs as well as in normal limbs, axons destined for both thigh and calf enter via the sciatic plexus. In view of the appropriate innervation of the remaining segment in partial limbs, we suggest that competitive interactions may play a role in organizing the projection via this plexus. These interactions may take place far proximally, producing a subtle order in the nerves entering the sciatic foramen, or they may occur more distally in the limb, or both. As in the spinal cord deletion experiments, we did not observe nerves expanding into territory they would not normally innervate. Whether there is in normal development a competitive interaction between thigh and calf motor axons is not clear from the present experiments. Such interactions may be more important in relation to innervation of the distal hindlimb, where the axons for many different muscles run in common in the peroneal and tibial nerves.

Conclusions. In summary, the results reported in this paper indicate a likely interplay of developmental mechanisms influencing the patterns of motor projections. It seems clear that motoneurons differ from one another in ways that are evident from their responses to cues at several different points along the growth paths. Pathway selection and guidance appear to be important in limiting nerve access to certain limb regions. In addition, competitive interactions within a neural pathway or between 
pathways that have overlapping termination zones, or possibly at the point of pathway selection, may be important in organizing the projection where more than one axon population normally has access to a given region. The experimental circumstances under which any given mechanism dominates can provide clues as to the way in which it exerts its influence during normal development (Hollyday and Grobstein, 1981).

\section{References}

Adams, J. C. (1977) Technical considerations on the use of horseradish peroxidase as a neuronal marker. Neuroscience 2: 141-164.

Bennett, M. R., R. Lindeman, and A. G. Pettigrew (1979) Segmental innervation of the chick forelimb following embryonic manipulation. J. Embryol. Exp. Morphol. 54: 141154.

Bennett, M. R., D. F. Davey, and K. E. Uebel (1980) The growth of segmental nerves from the brachial myotomes into the proximal muscles of the chick forelimb during development. J. Comp. Neurol. 189: 335-357.

Chu-Wang, I. W., and R. Oppenheim (1978) Cell death of motoneurons in the chick embryo spinal cord. II. A quantitative and qualitative analysis of degeneration in the ventral root, including evidence for axon outgrowth and limb innervation prior to cell death. J. Comp. Neurol. 177: 59-86.

Dennis, M. J., and J. W. Yip (1978) Formation and elimination of foreign synapses in adult salamander muscle. J. Physiol. (Lond.) 274: 299-310.

Hamburger, V. (1934) The effects of wing bud extirpation on the development of the central nervous system in chick embryos. J. Exp. Zool. 68: 449-494.

Hamburger, V. (1960) A Manual of Experimental Embryology, University of Chicago Press, Chicago.

Hamburger, V., and H. Hamilton (1951) A series of normal stages in the development of the chick embryo. J. Morphol. 88: 49-92.

Hanker, J. S., P. E. Yates, C. B. Metz, and A. Rustioni (1977) A new specific sensitive and non-carcinogenic reagent for the demonstration of horseradish peroxidase. Histochem. J. 9: 789-792.

Hollyday, M. (1980) Organization of motor pools in chick lumbar lateral motor column. J. Comp. Neurol. 194: 143-170.

Hollyday, M. (1981) Rules of motor innervation in chick embryos with supernumerary limbs. J. Comp. Neurol. 202: 439465.

Hollyday, M., and P. Grobstein (1981) Of limbs and eyes and neuronal connectivity. In Studies in Developmental Neurobiology. Essays in Honor of Viktor Hamburger, W. M. Cowan, ed., pp. 188-217, Oxford University Press, New York.

Hollyday, M., and V. Hamburger (1977) An autoradiographic study of the formation of the lateral motor column in the chick embryo. Brain Res. 132: 197-208.

Hollyday, M., V. Hamburger, and J. M. G. Farris (1977) Localization of motor neuron pools supplying identified muscles in normal and supernumerary legs of chick embryos. Proc. Natl. Acad. Sci. U. S. A. 74: 3582-3586.

Horder, T. J. (1978) Functional adaptability and morphogenetic opportunism, the only rules for limb development? Zoon 6 : 181-192.

Lamb, A. H. (1981) Target dependency of developing motoneurons in Xenopus laevis. J. Comp. Neurol. 203: 157-172.

Lance-Jones, C., and L. Landmesser (1980) Motoneuron projection patterns in embryonic chick limbs following partial deletion of the spinal cord. J. Physiol. (Lond.) 302: 559-580.

Lance-Jones, C., and L. Landmesser (1981a) Pathway selection by chick lumbosacral motoneurons during normal development. Proc. R. Soc. Land. B. 214: 1-18.

Lance-Jones, C., and L. Landmesser (1981b) Pathway selection by embryonic chick motoneurons in an experimentally altered environment. Proc. R. Soc. Lond. Biol. 260: 19-52.

Landmesser, L. (1978a) The distribution of motoneurons supplying the chick hindlimb muscles. J. Physiol. (Lond.) 284: 371-390.

Landmesser, L. (1978b) The development of motor projection patterns in the chick hindlimb. J. Physiol. (Lond.) 284: 391-414.

Landmesser, L., and D. G. Morris (1975) The development of functional innervation in the hindlimb of the chick embryo. J. Physiol. (Lond.) 249: 301-326.

Romanes, G. J. (1951) 'The motor cell columns of the lumbosacral spinal cord of the cat. J. Comp. Neurol. 94: 313-364.

Romanes, G. J. (1964) The motor pools of the spinal cord. In Organization of the Spinal Cord, J. C. Eccles and J. Schade, eds., pp. 93-119, Elsevier North-Holland, Amsterdam.

Romer, A. S. (1927) The development of the thigh musculature of the chick. J. Morphol. Physiol. 43: 347-385.

Saunders, J. W. (1948) The proximo-distal sequence of origin of parts of the chick wing and the role of the ectoderm. J. Exp. Zool. 108: 363-403.

Sperry, R. W., and H. L. Arora (1965) Selectivity in regeneration of the oculomotor nerve in the cichlid fish, Astronotus ocellatus. J. Embryol. Exp. Morphol. 14: 307-317.

Stark, R. J., and R. L. Searls (1973) A description of chick wing bud development and a model of limb morphogenesis. Dev. Biol. 33: 138-153.

Stirling, R. V., and D. Summerbell (1977) The development of functional innervation in the chick wing bud following truncations and deletions of the proximo-distal axis. J. Embryol. Exp. Morphol. 41: 180-207.

Summerbell, D., and R. V. Stirling (1981) The innervation of dorsoventrally reversed chick wings: Evidence that motor axons do not actively seek out their appropriate targets. J. Embryol Exp. Morphol. 61: 233-247.

Whitelaw, V., and M. Hollyday (1980) Motoneuron target selectivity in chicks with deleted, duplicated or reversed limb segments. Soc. Neurosci. Abstr. 6: 647.

Whitelaw, V., and M. Hollyday (1983a) Position-dependent motor innervation of the chick hindlimb following serial and parallel duplications of limb segments. J. Neurosci. 3: 12161225.

Whitelaw, V., and M. Hollyday (1983b) Neural pathway constraints in the motor innervation of the chick hindlimb following dorsoventral rotations of distal limb segments. J. Neurosci. 3: 1226-1233.

Wortham, R. A. (1948) The development of the muscles and tendons in the lower leg and foot of chick embryos. J. Morphol. 83: 105-148. 